Montoya Ruda, S. D., Mejía Macías, Y. A., Valencia Moreno, S. M., Cano Morales, L. J., y

Puerta Gil, C. A. (enero-abril, 2022). Mediación en el aula por medio de tecnologías de información y comunicación: reto de enseñanza y aprendizaje en quinto grado. Revista Virtual

Universidad Católica del Norte, (65), 66-101. https://www.doi.org/10.35575/rvucn.n65a4

\title{
Mediación en el aula por medio de tecnologías de información y comunicación: reto de enseñanza y aprendizaje en quinto grado
}

Mediation in the classroom through information and communication technologies: teaching and learning challenge in fifth grade

\author{
Sergio David Montoya Ruda \\ Especialista en Pedagogía de la Virtualidad \\ Institución Educativa Barrio París \\ Bello, Colombia \\ sergio.montoya.ruda@gmail.com \\ Orcid: https://orcid.org/0000-0001-7871-8010 \\ CvLAC: \\ https://scienti.minciencias.gov.co/cvlac/visualizador/generarCurriculoCv.do?cod rh=0001879271
}

\section{Yenifer Alexandra Mejía Macías}

Especialista en Pedagogía de la Virtualidad

Institución Educativa Barrio París

Bello, Colombia

yealme@hotmail.com

Orcid: https://orcid.org/0000-0003-4808-3338

CvLAC:

https://scienti.minciencias.gov.co/cvlac/visualizador/generarCurriculoCv.do?cod rh=0001879317

\section{Sandra Milena Valencia Moreno}

Especialista en Pedagogía de la Virtualidad

Institución Educativa Barrio París

Bello, Colombia

svalencia1231@hotmail.com

Orcid: https://orcid.org/0000-0003-4294-6032

CvLAC:

https://scienti.minciencias.gov.co/cvlac/visualizador/generarCurriculoCv.do?cod_rh=0001879852 


\title{
Lady Johana Cano Morales
}

Especialista en Pedagogía de la Virtualidad

Institución Educativa Barrio París

Bello, Colombia

ladycano2714@gmail.com

Orcid: https://orcid.org/0000-0002-6658-0998

CvLAC:

https://scienti.minciencias.gov.co/cvlac/visualizador/generarCurriculoCv.do?cod_rh=0001879317

\author{
Carlos Augusto Puerta Gil \\ Magíster en Educación \\ Coordinación de Investigaciones e Innovación, Fundación Universitaria Católica del Norte \\ Medellín, Colombia \\ cpuertagil@gmail.com \\ Orcid: https://orcid.org/0000-0002-9218-0082 \\ CvLAC: \\ https://scienti.minciencias.gov.co/cvlac/visualizador/generarCurriculoCv.do?cod_rh=0000793310
}

Recibido: 30 de mayo de 2021

Evaluado: 20 de septiembre de 2021

Aprobado: 21 de enero de 2022

Tipo de artículo: Investigación Científica y Tecnológica.

\section{Resumen}

La investigación se planteó al visualizar el interés que tenían los educandos de la Institución Educativa (IE) Barrio París, específicamente del grado quinto, en aprender a emplear adecuadamente, en el ámbito educativo, las tecnologías de la información y la comunicación (TIC), en las que están inmersos desde muy temprana edad. Motivo por el cual se propuso analizar las incidencias que tienen las TIC en el proceso de enseñanza y aprendizaje bajo su mediación pedagógica. Para su desarrollo se tuvo en cuenta una muestra poblacional de 38 estudiantes, los cuales se seleccionaron basados en un proceso no probabilístico. Además, se recurrió a la metodología cualitativa y al diseño de investigación acción participativa. Esto permitió aplicar diferentes técnicas, entre las cuales se encontraban: revisión documental, entrevista semiestructurada, observación cualitativa y foros virtuales. Finalizada esta etapa, surgieron los resultados diferenciados en las siguientes categorías: incidencia de las TIC y su mediación dentro de la IE, ventajas de su mediación en la enseñanza y sus contribuciones en el aprendizaje. Estos hallazgos, contrapuestos a teorías y resultados de otras investigaciones, permitieron demostrar su 
incidencia favorable en el proceso educativo, con mejoras visibles en actos como participación, innovación en el aula y la concentración de la atención.

Palabras clave: Aprendizaje; Enseñanza; Incidencia; Mediación pedagógica; Participación; Tecnologías de la información y la comunicación.

\begin{abstract}
The research was proposed to visualize the interest of the students of the Educational Institution (IE) Barrio París, specifically of the fifth grade, in learning how to properly use information and communication technologies (ICT) in the educational environment, in which they are immersed from a very early age. For this reason, it was proposed to analyze the impact of ICT in the teaching and learning process under its pedagogical mediation. For its development, a population sample of 38 students was taken into account, which were selected based on a non-probabilistic process. In addition, the qualitative methodology and the participatory action research design were used. This allowed the application of different techniques, among which were: documentary review, semi-structured interview, qualitative observation and virtual forums. At the end of this stage, the results were divided into the following categories: incidence of ICT and their mediation within the IE, advantages of their mediation in teaching and their contributions to learning. These findings, in contrast to theories and results of other research, made it possible to demonstrate their favorable impact on the educational process, with visible improvements in acts such as participation, innovation in the classroom and concentration of attention.
\end{abstract}

Keywords: Learning; Teaching; Advocacy; Pedagogical mediation; Participation; Information and communication technologies.

\title{
Introducción
}

Con el pasar del tiempo las TIC están cada vez más presentes en las nuevas generaciones, lo cual conlleva a que nazcan, crezcan y se desarrollen con su influencia (Mosquera-González et al., 2021). De esta manera, se genera una familiarización con este tipo de tecnologías desde muy 
temprana edad. Sin embargo, la aparición de este tipo de herramientas en el aula de clase está llegando de una forma muy paulatina. Generalmente, este tipo de ayudas audiovisuales son poco utilizadas en las IE, lo que ha impedido la adquisición de nuevas estrategias que pueden surgir a través de la mediación de este tipo de instrumentos. Su uso, aunque ya conocido en la mayoría de las instituciones, se ve habitualmente opacado por metodologías tradicionalistas.

Por lo anterior, la investigación se fundamenta en las nuevas tecnologías y los métodos de enseñanza actual. Busca analizar la relación existente entre sí, para determinar cómo podría impactar la implementación de herramientas virtuales en el aula de clase. Esto se hace necesario, porque la escuela no puede caminar para lados opuestos a lo que la sociedad implementa como forma de vida actual. Por ello, este análisis supone una consolidación coherente entre la escuela y la sociedad. Atendiendo a que la apertura tecnológica y el acceso permanente a estas plataformas es cada vez más constante, la educación debe tomar medidas pedagógicas para resignificar las prácticas pedagógicas y, de esta manera, el acto de enseñanza y aprendizaje (Patiño-Toro et al., 2020).

Por esta razón, la investigación "Mediación en el aula por medio de TIC: reto para la enseñanza y aprendizaje en quinto grado", tiene en cuenta exploraciones anteriores que pueden aportar información significativa. Como botón de muestra, en la investigación realizada por Gómez y Álvarez (2020): "se considera al uso de las computadoras y otros dispositivos digitales como una demanda social ya instalada en la cotidianeidad y en la vida general de los sujetos, especialmente en las instituciones educativas a las que pertenecen" (pp. 15-16). Lo anterior, es evidenciado en cada una de las instituciones educativas actuales, las cuales ven cada día la necesidad de implementar aulas especializadas para la enseñanza de competencias en las herramientas virtuales.

El crecimiento acelerado de la sociedad ha llevado a las diferentes organizaciones a replantear sus métodos y formas de ver la educación (Borrero-Puentes \& Alcalá-Zarate, 2020). Así lo mencionan Carneiro et al. (2019): "el diseño de los nuevos currículos y la práctica de la enseñanza han de tener en cuenta a sus destinatarios" (p. 7). Esto implica la necesidad de estudiar las diferencias culturales, sus características, necesidades y hábitos poblacionales, con el fin de estructurar y aplicar de manera correcta a la población en estudio. 
Por su parte, Hernández (2017) expresa que no basta con implementar las TIC en el aula, sino darle sentido. Es decir, aprovechar de maneras diversas y permanentes estas plataformas, en función de una consolidación del conocimiento, con base en la tecnología (p. 329). Por consiguiente, el impacto que tienen estas herramientas en el aula de clase, donde son empleadas, genera grandes retos en la estructura, modalidad y metodologías practicadas.

Un aspecto que preocupa fue expuesto por la investigación de Espinel Armas (2020) aludiendo a que "aunque hay diversidad de herramientas, son susceptibles de ser mal utilizadas, por parte del alumnado durante el proceso educativo como un elemento distractor, y por docentes al no incorporarlas de manera planificada en el aula" (p. 8). Dando por enterado que, así como se mencionó en el párrafo anterior, las tecnologías mal utilizadas solo cumplen con un papel de entretenimiento, más no de reflexión y socialización académica; un aspecto que se debe entretejer pertinentemente desde su planeación y ejecución.

Así las cosas, debido a que la mediación de las TIC puede traer consigo diferentes incidencias, positivas o negativas, es necesario realizar un análisis que permita validar si su profundización en el campo de la educación es pertinente. En consecuencia, es importante aclarar que el presente proyecto centra su análisis en la mirada de los estudiantes y docentes, y el reto que representa para ellos la inclusión de estas herramientas en el aula, teniendo en cuenta que son ellos quienes vivencian la incidencia de las TIC como mediación pedagógica; sus experiencias y conocimientos son de gran relevancia para la presente investigación.

De este modo, y partiendo de la voz de los participantes, se realiza un análisis que permite profundizar la presente investigación, mediante las teorías afines al tópico de esta. En este último aspecto, se tienen como fundamentos teóricos a autores como Siemens (2004/2007), con Conectivismo; una teoría de aprendizaje para la era digital. Allí se fundamentan los aportes en la inclusión de las TIC como complemento a los procesos formativos. Por otra parte, se presenta Ausubel (1983) y su Teoría del aprendizaje significativo, la cual se basa en los aspectos que hacen posible una adquisición a tal profundidad, debido a que la mediación del aprendizaje, por medio de las TIC, permite a los estudiantes conectar los nuevos conceptos con aquellos que ya conocen de forma previa. Y, finalmente, con los aportes de Hernández Requena (2008) y su texto "El modelo constructivista con las nuevas tecnologías: aplicado en el proceso de aprendizaje", se analiza la mediación de estas herramientas en los espacios educativos. Por ende, al implementar 
las TIC en clase, se observa una mayor participación, creatividad y autonomía por parte de los educandos. Es decir, las nuevas tecnologías favorecen los procesos de formación.

De esta manera, este análisis tripartito permite responder los tres objetivos de investigación. Primero, describir la incidencia que puede generar la aplicación de las TIC como mediación pedagógica. Segundo, evaluar las ventajas de los procesos de enseñanza mediados a través de las TIC. Y, tercero, detallar cómo las TIC, con su mediación pedagógica, contribuyen en la adquisición de aprendizajes de los estudiantes. Por esta razón, se logra resolver el modo en que incide la aplicación de estas herramientas como mediaciones pedagógicas en los procesos de enseñanza y aprendizaje.

Así pues, se considera que con la actual investigación no solo se posibilita la transformación del escenario educativo en la institución analizada; también, sirve de referente para otras realidades de establecimientos educativos alternos. Además, se busca beneficiar al equipo docente, quienes podrán conocer la incidencia del uso de las TIC y aplicar estos hallazgos en sus clases.

En este orden de ideas, se expone inicialmente la metodología utilizada en la investigación. En ella se encuentra la ruta que se lleva a cabo para dar respuesta a la pregunta planteada. Seguidamente, se exhiben los resultados producto del análisis cualitativo realizado. Y, finalmente, se presentan las discusiones y conclusiones de la investigación.

\section{Metodología}

Para efectos del desarrollo del proyecto se realizó una investigación de corte cualitativo, la cual consiste, según Hernández Sampieri et al. (2018), en que "el investigador comienza el proceso examinando los hechos en sí y revisando los estudios previos, ambas acciones de manera simultánea, a fin de generar una teoría que sea consistente con lo que está observando" (p. 7). Así las cosas, se fundamentó en su flexibilidad para las retroalimentaciones.

Por otro lado, se enmarcó en un diseño de investigación-acción participativa, en la cual, según Hernández Sampieri et al. (2018), "los participantes pueden fungir como coinvestigadores ya que necesitan interactuar de manera constante con los datos" (p. 534). De esta manera, los participantes intervinieron de una forma colaborativa y dinámica con la información recolectada, 
aportando percepciones frente al objeto de estudio. En concreto, se basó en una forma natural de proceder, que se centró en los actores, tomando así las perspectivas de los participantes. Para ello se tuvo en cuenta las siguientes fases: recolección y tabulación de información, socialización, debate, replanteamiento de hallazgos y conclusiones. Actos que fueron realizados bajo un proceso cíclico.

Todo lo anterior se realizó en la Institución Educativa Barrio París del municipio de BelloAntioquia, enfocado en una población de 115 estudiantes, los cuales pertenecieron a los grados quinto de primaria. Sus edades oscilaban entre los 9 y 14 años. Además de esta, la comunidad contaba con otras características similares: grado escolar, docentes, procesos académicos, sitios escolares y, en general, la misma zona sociocultural.

Para la aplicación de los instrumentos, se tuvo en cuenta un grupo más selecto bajo un proceso no probabilístico, en el cual los factores influyentes fueron independientes, por lo que solo se necesitó una muestra pequeña para obtener resultados rápidos (Wang \& Xiong, 2019, p. 1). Ello para respaldar los resultados, como si se hubiesen aplicado en toda la colectividad; es decir, esta población se especificó en un subgrupo para recolectar los datos, dependiendo de los intereses investigativos.

Es por ello por lo que se puntualizó como muestra a un grupo de 38 estudiantes pertenecientes al grado quinto de la IE en estudio. Fueron seleccionados bajo una muestra casotipo, la cual, según Agudelo Ceballos y Valencia Arias (2018) "se aborda a partir de la comparación entre la teoría previamente expuesta y el ejercicio práctico al interior" (p. 28). Su selección estuvo relacionada con los propósitos y las necesidades del investigador (conectividad y dispositivos electrónicos). En dicha elección se utilizaron los siguientes elementos:

Entrevistas semiestructuradas: se aplicaron a los docentes preguntas preestablecidas ampliadas en el momento de la entrevista, según su necesidad.

Observación cualitativa: se abordaron los diarios de campo que hicieron los docentes en el ejercicio de su labor; tomando parte del entorno, participando con los individuos y registrando sus observaciones analíticamente alrededor del tema investigado.

Revisión documental: se revisaron fuentes teóricas que dieron soporte a las observaciones y hallazgos encontrados, que fundamentaron y explicaron, desde la teoría, la realidad de la investigación. 
Foro electrónico: se tomó la voz del estudiante alrededor de una pregunta moderadora. Este espacio de opinión permitió a los investigadores acercarse a la realidad de los participantes, captando su sentir, pensar y vivir.

Por otra parte, para efectos de validación de este proyecto, la muestra seleccionada pasó por dos principales aspectos de recolección. Inicialmente, la información primaria asentada en las teorías de autores como Hernández Requena (2008), Siemens (2004/2007) y Ausubel (1983). Seguidamente, una recolección secundaria, pues se contó con los testimonios de estudiantes y profesores del grado quinto de dicha Institución. De esta manera, fueron recopilados los datos necesarios para su desarrollo. Para finalizar, la observación participante fue una fuente esencial, en tanto permitió captar testimonios, partiendo de los diferentes sentidos de las personas mediadoras en el proceso de enseñanza y aprendizaje de la muestra seleccionada.

De igual modo, la entrevista proporcionó un factor primordial que ofreció referencias de primera mano por parte de los estudiantes seleccionados y sus docentes. Además, partiendo de los objetivos específicos, se determinaron como categorías de análisis: la mediación pedagógica, sus ventajas en el proceso de enseñanza, y sus contribuciones en el aprendizaje, las cuales, al aplicar los instrumentos mencionados anteriormente, emanan unas subcategorías que permitieron decodificar la información, gracias a los testimonios de los participantes.

\section{Resultados}

A continuación, se presentan los resultados de la investigación, lo cuales emergieron a partir de la aplicación de las técnicas de recolección de información, con el fin de obtener respuestas a la pregunta planteada. Específicamente, para la presente IE se buscaba analizar el modo en que incide la aplicación de las TIC como mediación pedagógica en los procesos de enseñanza y aprendizaje. Sin embargo, a partir de los hallazgos identificados fue surgiendo un sistema de categorías, el cual se encuentra preestablecido por la interrogación en mención. De esta manera, este sistema cuenta con tres categorías iniciales: la incidencia de las TIC como mediación pedagógica, sus ventajas en la enseñanza y las contribuciones en el aprendizaje, categorías que están estrechamente emparentadas con los objetivos específicos de la presente investigación. 
Finalmente, a través de la sistematización de datos, en cada una de las categorías iniciales surgió un sistema categorial emergente, que surge de la voz de los participantes, tanto estudiantes como docentes, actores principales en esta investigación. Es decir, fueron emanando subcategorías que complementan el grupo genérico. Estas se detallan en cada uno de los puntos que se verán a continuación.

\section{Incidencia de las TIC como mediación pedagógica}

La evolución de las TIC, en los diversos ámbitos de la sociedad, ha generado nuevos desafíos para la formación de la comunidad y de las personas (Yong Castillo et al., 2017, p. 83). En el caso de las IE, se puede evidenciar que, paulatinamente, las TIC ganan más terreno en las aulas de clase. Esto favorece la creación de espacios mediados pedagógicamente por sus diferentes herramientas.

Ahora bien, para la comprensión adecuada de esta primera categoría, vale la pena aclarar que las TIC tienen un papel de facilitador o mediador entre los estudiantes y el contenido. No obstante, su papel se establece como mediador pedagógico "cuando se convierte en un procedimiento por el cual el 'mediador' — uno de los tres integrantes de la tríada docente - alumno -contenido-, logra facilitar la resolución de un conflicto cognitivo entre las otras dos partes intervinientes" (Puerta Gil, 2016, p. 4). En otras palabras, las categorías emergentes que se verán a continuación pretenden connotar la diversidad de incidencias que facilitan la educación, a través de la mediación de dispositivos y medios de comunicación digitales.

Por otra parte, es pertinente aclarar que el término incidencia está descrito en ambos campos, cualitativo y cuantitativo. Sin embargo, es oportuno tenerlo en cuenta para esta investigación bajo su aspecto cualitativo. Es decir, "se trata, en definitiva, de integrar lo técnico y lo social" (Arriazu Muñoz, 2015, p. 228). Por tanto, se refiere a los sucesos o influencias observadas y evidenciadas analíticamente en la muestra seleccionada.

A continuación, se describen las principales incidencias que tienen las TIC como mediación pedagógica en los procesos educativos. Las cuales, partiendo de sus generalidades, pueden influir positivamente en los procesos educativos de cualquier IE. 


\section{Motivación}

A partir de los datos recolectados, una de las incidencias que emergió por el uso de las TIC, como mediación pedagógica, fue la motivación. Esta surgió en los estudiantes al aprender mediante la interacción con las TIC. Es conveniente señalar que este término tiene varias connotaciones en pedagogía; pero se considera pertinente la concepción de Albrecht \& Karabenick (2018), al mencionar que la motivación se puede describir como el aumento de la relevancia y el valor de la actividad pedagógica, lo cual debe influir en la generación de compromiso con las tareas académicas (pp. 2-5). Así las cosas, se debe entender la motivación como una acción fundamental que fortalece, significativamente, los procesos académicos de los estudiantes. Por otra parte, se debe resaltar que la motivación activa en ellos la determinación y la persistencia necesaria, académicamente, para el cumplimiento de las actividades escolares; motivo por el cual, entre actividades y motivación, debe haber una reciprocidad que favorezca los procesos académicos y la actitud de los estudiantes frente a los mismos.

Las TIC son herramientas que se caracterizan por su diversidad de estrategias, su innovación y el rol que ofrecen al estudiante en el desempeño de actividades. Estas cualidades son factores que activan la motivación. Al respecto, como lo manifiesta el Docente 1, "las TIC influyen mucho hoy en día en el estudiante ya que (...) permite [sic] una mayor disposición para aprender por parte de los educandos a través de la motivación". Por otra parte, los estudiantes argumentan que son más motivadoras las clases mediadas por TIC, debido a que permanecen con más "deseos de seguir trabajando" (Estudiante 3), y les da "motivación para asistir" a este tipo de clases (Estudiante 2). Lo anterior, reveló el interés de participar en clases mediadas por TIC y la motivación que genera en ellos. Además, implementar las TIC en clase propicia espacios que activan al estudiante, los llena de entusiasmo, disposición, y evita la asistencia forzosa a las aulas de clase.

Ahora bien, es importante remarcar expresiones y calificativos de los estudiantes y docentes al utilizar adjetivos, como mayor o gran, para indicar el grado o el nivel de su motivación respecto a la implementación de las TIC en clase. Estas afirmaciones evidencian la capacidad de las TIC en el fomento de la motivación de los educandos, a partir de su diversidad de cualidades. Estas herramientas transforman los contenidos, los vuelven más atractivos visual, pedagógica y 
lúdicamente, lo cual contribuye en su motivación e interés, continuidad y desarrollo de actividades. Todo esto propicia la participación del estudiantado, su total inmersión en el contenido propuesto y, por ende, favorece un aprendizaje más impactante y significativo en ellos. A partir de ello, se pueden aprovechar dichas ventajas para mantener activo el estado anímico de los estudiantes en clase y mejorar su proceso académico.

Lo anterior, se debe a la relevancia y el valor agregado que genera la virtualidad en los estudiantes. Las TIC son herramientas que activan su participación, los convierte en seres que requieren y piden este tipo de herramientas. Por lo cual, interactuar con estas tecnologías en clase permite aprovechar la disposición y actitud de los estudiantes con este tipo de herramientas. El trabajo con elementos familiares permite que ellos se desenvuelvan en clase, desarrollen sus conocimientos previos y los vuelvan significativos desde el contenido que se quiere abordar.

En definitiva, es importante que los docentes favorezcan el proceso educativo mediante la fascinación que tienen los estudiantes por el uso de las TIC; así pues, beneficiar el acto de enseñanza y aprendizaje con la mediación de recursos ofrecidos por estas herramientas, como los juegos educativos (gamificación) o recursos interactivos. Estas actividades, debido a que son atractivas para los educandos, los incentiva a participar, desarrollar y trabajar en ellas. Como lo indica Porcar Marín (2018) "es una posibilidad interesante que tienen los docentes en sus manos para solucionar problemas de motivación o falta de participación" (p. 31). Estas mediaciones pedagógicas, aparte de demostrar incidencias positivas en la motivación, son una de las actividades más solicitadas por los estudiantes. La recompensa de responder adecuadamente, hacer la actividad antes del "pitido del cronómetro" y la competitividad que ofrece este tipo de mediaciones, en forma de juegos y recursos, los convierte en una herramienta eficaz a la hora de adquirir y reforzar conocimientos. Por otra parte, su implementación puede asumir un rol fundamental a la hora de discernir entre el entendimiento o no del contenido.

\section{Concentración de la atención}

Otra incidencia encontrada a lo largo de este proceso investigativo es la concentración de la atención. Acatando la concepción de Ortiz Ocaña (2015), se entiende por concentración a la capacidad de discriminar la información irrelevante y focalizar la relevante. Por otra parte, la 
atención hace referencia a la selección de información sensorial, su dirección a procesos mentales y la búsqueda consciente o inconsciente de un objetivo, lo que conlleva a procesos neurofisiológicos (p. 78). No obstante, no son actos diferenciados; la concentración hace referencia a un proceso netamente mental. Por su parte, la atención refiere a los procesos físicos necesarios para poder concentrarse. En definitiva, la concentración de la atención refiere a la capacidad de discriminar la información innecesaria (concentrar) y permitir la adquisición neurofisiológica de la necesaria (atender).

En los actos educativos deben estar presentes ambas para poder focalizar el acto de aprendizaje. En primer lugar, el estudiante debe tener un objetivo de aprendizaje, lo que permitirá preparar sus procesos neurofisiológicos para el acto. En un segundo momento, el estudiante tendrá que concentrar su atención para poder discriminar la información innecesaria y poder asimilar el acto educativo.

Respecto a esto, Ortiz Ocaña (2015) indica que la atención se logra a partir de estímulos (intereses, expectativas, experiencias, necesidades) que sean novedosos para los estudiantes. Por ello, no se debe pedir al estudiante que concentre su atención; se debe diseñar estrategias que lo propicien (pp. 77-78). En este caso, conociendo la gran motivación que genera en ellos las clases mediadas por TIC, se puede emplear en su proceso de atención para que la concentren, en totalidad, en el acto académico.

En torno a esto, los docentes de la IE manifiestan que es "evidente" la concentración de los estudiantes. También, aclaran que los educandos "atienden" y "prestan más atención" en las clases que están mediadas por TIC, versus las clases sin este tipo de mediaciones. Lo anterior, parte del hecho de la innovación, fascinación y agrado que representa para los escolares participar en clases mediadas por estas herramientas. En este sentido, la inclusión de las TIC en el aula de clase posibilita presentar los contenidos con estrategias más atractivas, que impactan a los estudiantes a través de diversos sentidos. Esto se debe a que se generan escenarios novedosos, que movilizan la atención de los estudiantes y favorecen su aprendizaje.

Mediante las observaciones realizadas en la Institución, se pudo identificar diferencias notables en la concentración de la atención en clases presenciales mediadas con TIC, respecto a clases de esta misma índole, pero sin este tipo de mediaciones. Las clases tradicionales, en su mayoría centradas en un enfoque magistral, limitan las cualidades pedagógicas del acto de 
enseñanza. Estas metodologías se enfocan en el docente y olvidan las individualidades de aprendizaje del estudiante; además, sus estrategias están altamente dirigidas a un solo sentido sensorial: el oído.

Por otra parte, las clases mediadas con TIC ofrecen herramientas atractivas e impactantes. Sus estrategias se caracterizan por ofrecer contenidos novedosos, con diferentes formas, tamaños, colores, sonidos, figuras, percepciones; entre muchas otras características. En este tipo de clases intervienen muchos más sentidos en la adquisición de información, lo cual permite obtener, procesar y adaptar más datos del entorno. Por ello, es vital que los docentes distingan herramientas que permitan impactar y activar esta riqueza sensorial. Con este tipo de estrategias se habilita la posibilidad de detonar en el estudiante más canales sensoriales, y, entre más de ellos sean captados, más significativo será el aprendizaje. De esta manera se logra mejorar su concentración de atención y, por ende, la capacidad de enfocarse en los contenidos y actividades propuestas en clase.

\section{Participación}

Una tercera incidencia en la utilización de las TIC como mediación pedagógica es la participación. En palabras de los docentes, con ellas se evidencia estudiantes "más participativos", "más activos" (Docente 4) y mejora la "participación de los estudiantes más tímidos" (Docente 1). Esto se debe a la diversidad de medios de comunicación, sincrónicos y asincrónicos, que favorecen sus necesidades comunicativas. Es decir, las actividades mediadas por herramientas tecnológicas inciden en la forma en que los estudiantes se comunican entre ellos y sus docentes. Al diversificar por medio de blogs, chats, foros, muros (entre muchas otras opciones), el proceso comunicativo, se beneficia el canal adecuado y/o necesario para que ellos puedan expresar con facilidad sus ideas.

Respecto a lo anterior, Hernández Requena (2008) indica que en investigaciones anteriores se ha "demostrado que los ordenadores proporcionan un apropiado medio creativo para que los estudiantes se expresen y demuestren que han adquirido nuevos conocimientos" (p. 5); argumentando lo expuesto en la presente investigación. Sin embargo, lo que resalta más en la mediación de las TIC en este aspecto, es la diversidad de medios y estrategias que fortalecen la participación estudiantil. Principalmente, considerando que a través de las diferentes herramientas que contienen, se pueden eliminar factores externos que impiden su adecuada participación. Como 
botón de muestra, se evidencia que el temor a un público observante es eliminado cuando la intervención es mediada por herramientas tecnológicas.

Respecto a metodologías tradicionales, donde predomina la oralidad frente al público como medio comunicativo, la mediación pedagógica con herramientas tecnológicas cuenta con muchas más alternativas comunicativas. En este tipo de mediación no solo está presente la expresión oral; la participación mediante foros, formularios virtuales, chats, juegos, videos y otros medios comunicativos, entregan una alternativa de opinión e inhiben al estudiante del temor al público. Datos que se vuelven evidentes en las observaciones realizadas, donde el temor a participar en las clases con metodología tradicionalista es notorio; en este tipo de clases pocos estudiantes se motivan a hablar, aunque el docente genere preguntas. Sin embargo, las clases mediadas por TIC muestran grandes intervenciones a través de las diversas herramientas empleadas.

Por otra parte, los diferentes enlaces, páginas, aplicaciones, redes sociales y recursos multimedia mantienen informados y comunicados a los padres de familia, lo cual activa su participación en el proceso educativo de los estudiantes. La incorporación de las TIC en la escuela, como lo indica Macià Bordalba (2016), ha facilitado la comunicación familia-escuela; estas herramientas han posibilitado nuevas perspectivas que permiten cerrar la brecha comunicativa que había entre estos dos integrantes de la comunidad académica (pp. 74-75). Por ende, la mediación de las TIC en los procesos académicos de los estudiantes no solo incide en la participación de estos; su implementación también favorece la comunicación e intervención de los padres de familia en el proceso educativo.

Mantener a los padres de familia informados sobre los procesos académicos de los estudiantes, sin duda alguna, fortalece sus procesos académicos. Se evidencia que, mediante este tipo de comunicación, los padres de familia están más informados de las actividades a desarrollar por parte de los estudiantes, lo cual mejora el cumplimiento de estas. Además, permite agilizar los procesos comunicativos y, por ende, una mayor participación de padres de familia en actividades escolares en las que deben estar presentes. Sin embargo, según Macià Bordalba (2016) se evidencia una tendencia a utilizar más los canales de comunicación unidireccional; es decir, el proceso comunicativo es efectivo en sentido institución-padres de familia, pero no se emplea adecuadamente en forma viceversa (pp. 74-75). Motivo por el cual, un reto para los docentes es implementar canales que permitan una comunicación efectiva entre ambas partes. 


\section{Innovación tecnológica}

Otra incidencia de las TIC como mediación pedagógica surge de las expresiones de los docentes, quienes consideran la implementación de las TIC en la formación de los estudiantes como un aspecto innovador en las clases. En sus propias voces, expresan que "las tecnologías nos permiten innovar" (Docente 3), "estar a la vanguardia" (Docente 2), "Innovar en la didáctica" (Docente 4) y "es algo novedoso" (Docente 2). Encontrándose en sus expresiones que la inclusión de este tipo de herramientas incide en la forma de ver la Institución; aportando nuevos avances y fortaleciendo las necesidades que presenta la comunidad educativa.

Téngase en cuenta que los estudiantes se encuentran inmersos en medio de los avances tecnológicos, especialmente por el uso constante del Internet y los dispositivos electrónicos. Sin embargo, son herramientas que aún no son muy frecuentes en las IE. Aspecto que fue claramente observado en el año 2020 por la pandemia generada por el COVID-19. En ese momento se comenzaron a incluir las TIC como mediación pedagógica para garantizar el derecho a la educación, lo que evidencia que la mediación de las TIC puede incidir como una innovación pedagógica para dar respuesta a problemáticas que surgen al interior de las IE. Al respecto, como lo indica Pérez-Ortega (2017), las TIC pueden ser mediadores innovadores en la educación de los estudiantes; no obstante, es de vital importancia el evitar repetir la misma metodología tradicionalista o magistral, pero con nuevas herramientas. De esta forma la innovación pierde sentido, pues se estaría siguiendo el mismo modelo y solo se estarían cambiando algunos elementos en este proceso (pp. 252-253). Lo anterior, evidencia que la implementación y mediación de las TIC en clase permite actualizar las IE. Pero el reto educativo está en la capacidad de los docentes para innovar también la práctica pedagógica, y así responder a las necesidades didácticas e intereses de la sociedad para la cual educan.

Por tanto, a lo que respecta en la educación sobre innovación tecnológica, es necesario que los docentes descubran y apliquen nuevas herramientas en las IE. Las TIC ofrecen diferentes recursos que inciden positivamente en los procesos educativos de los estudiantes, y ellos mismos expresan su gusto por estas herramientas. Frases como "me gusta que ya podemos utilizar el celular para hacer actividades de clase" (Estudiante 27) y "es algo novedoso" (Estudiante 10) evidencian 
la estrecha relación que tienen con los dispositivos electrónicos y el agrado que les genera el emplearlos para sus procesos académicos.

Innovar en la educación, no solamente hace referencia a que el docente entregue contenidos con ayuda de las TIC; también, hace énfasis en la empleabilidad de las herramientas que los estudiantes utilizan en casa, pero que fueron estigmatizadas en el aula de clase como objetos distractores. Por ello, es necesario aclarar que estas herramientas poseen grandes innovaciones a favor de los procesos educativos, en tanto, siendo bien empleadas, pueden incidir no solo como innovación tecnológica, sino, también, propiciando la adquisición de aprendizajes significativos en los estudiantes.

En síntesis, innovar pedagógicamente con las TIC hace referencia a la implementación de las herramientas tecnológicas que permitan diseñar nuevas estrategias en el aula de clase. Actividades como la gamificación, exploración de lugares de forma virtual (museos, teatros, las maravillas del mundo), evaluaciones virtuales, arte audiovisual, libros digitales, entre muchas otras opciones, innovan la forma en que se ofrece el contenido a los estudiantes. Estas estrategias deben ir orientadas bajo ideales nuevos que permitan mejorar la práctica educativa, su productividad y, más precisamente, el proceso de aprendizaje de los educandos. Deben estar encaminadas en eliminar la monotonía, el tradicionalismo, la rutina y los tiempos muertos en clase.

Por ende, implementar las TIC en la educación no solo actualiza a la escuela para responder a una sociedad inmersa en la tecnología; además, posibilita a los docentes automatizar procesos y mejorar tiempos de tutoría. Lo anterior, debido a que se agilizan procesos de calificación, respuestas de actividades y digitación de notas (Alarcón et al., 2015, p. 68). Por lo que mediar la educación con ayuda de las TIC, incide en la innovación necesaria para afrontar una era tecnológica.

\section{Ventajas de la mediación de las TIC en la enseñanza}

A pesar del largo tiempo que lleva instaurada la enseñanza en la humanidad, son pocos los cambios que se han visto en las aulas de clase. Lo anterior, no solo en la forma de ser transmitida, sino también en los contenidos abordados por las diferentes áreas. De forma contraria, las TIC son un conjunto de herramientas que se destacan por su evolución y desarrollo. Por eso, esta segunda 
categoría analiza las ventajas de un proceso de enseñanza mediado por ellas. Vale la pena aclarar que en esta investigación se toma como ventaja a aquellas condiciones que favorecen el acto educativo; motivo por el cual, para las siguientes subcategorías, se destacan esas favorabilidades en la enseñanza que puede ofrecer una educación mediada pedagógicamente por TIC.

\section{Variedad de herramientas tecnológicas}

La variedad de herramientas es la primera ventaja analizada en la medicación de las TIC en el proceso de enseñanza. Los múltiples equipos y recursos tecnológicos ofrecen una gran "variedad de opciones" (Docente 2) en el aula de clase. Estas posibilitan una inmensa diversidad de estrategias para los diferentes procesos educativos. Esta variedad propicia el desarrollo de actividades de acuerdo con las capacidades, necesidades, ritmos y formas de adquisición de aprendizaje de los estudiantes. También, "aportan estrategias significativas" (Docente 2) al proceso de enseñanza.

La diversidad tecnológica permite explicar de forma novedosa y con diferentes contenidos en distintas áreas. También, convierte a los estudiantes en parte activa y dinámica de las clases; es decir, pasan de ser solo receptores del conocimiento a creadores y constructores de este.

Respecto a lo anterior, Hernández Requena (2008) indica que las TIC ofrecen diferentes alternativas que "permiten que el aula tradicional se convierta en un nuevo espacio, en donde tienen a su disposición actividades innovadoras de carácter colaborativo y con aspectos creativos que les permiten afianzar lo que aprenden al mismo tiempo que se divierten" (p. 3). En consecuencia, la diversidad didáctica que se puede conseguir con la implementación de las TIC fomenta espacios creativos, participativos y atractivos en el acto de enseñanza.

Por otra parte, las vivencias de los docentes les permiten interpretar que las TIC "aportan estrategias significativas" y gran "variedad de opciones" (Docente 3); lo cual, partiendo de la necesidad de diversificar las estrategias pedagógicas, se adhiere como un aspecto primordial a favor de las TIC en la enseñanza. Además, como lo indica Benítez Díaz et al. (2019), se debe tener en cuenta la diversidad de herramientas que están propiciando los sectores tecnológicos, los cuales cada vez muestran mayor interés en desarrollar servicios y productos que favorezcan la enseñanza a través de la mediación de las TIC (p. 91). En este caso, el reto de los docentes va más allá de la 
implementación de estas herramientas en clase. Los docentes deben estar centrados en identificar las herramientas que activan al estudiante y lo muevan de su pasividad educativa. Es preciso aprovechar que la variedad de herramientas que tienen las TIC cuenta con la capacidad de detonar los intereses de los estudiantes a través de su diversidad como mediador pedagógico. En concreto, las TIC transmiten contenidos más acordes al interés y contexto de los estudiantes, y fomentan un diseño de clase innovador y con mayor impacto.

\section{Trabajo en equipo virtual}

Otra ventaja evaluada en los procesos de enseñanza mediados por las TIC es el trabajo en equipo. Inicialmente, es importante resaltar que el ser humano es un ser social y requiere de otros para poder desarrollarse a plenitud. De igual modo, en la educación, él requiere de otros para detonar sus habilidades, conocimientos y enriquecer sus saberes. Esto, con ayuda de las TIC, permite observar "un trabajo en equipo donde se colaboran unos a otros en las dudas que surgen" (Docente 1), lo que a su vez desarrolla su proceso de aprendizaje.

Respecto a lo anterior, Hernández Requena (2008) postula que el trabajo en equipo ofrece a los estudiantes "una identidad social, que los hace sentir entusiasmados, y les estimula logrando que tengan ganas de aprender y que se sientan felices al realizar las actividades relacionadas con el proceso" (p. 31). Por lo cual, el diálogo constante entre estudiantes, bajo las diversas herramientas tecnológicas (chat, correo, videollamadas, entre otros), aumenta su vocabulario, conocimiento y amplía o modifica sus ideas. Aspecto resaltado por estudiantes y docentes, donde aclaran que las TIC permiten "conectarnos en equipo" (Estudiante 9), y de esta manera "desarrollar el aprendizaje entre pares" (Docente 4).

\section{Mejoramiento de la explicación}

Ahora bien, las mejoras en la explicación de contenidos es el siguiente aspecto para evaluar. Es inevitable pensar en las TIC como esa caja de herramientas que "permiten explicar de diferentes formas para que (...) puedan entender" (Docente 1). Esta variedad de instrumentos posibilita 
diversificar las estrategias e innovar en la didáctica. De esta manera se puede usar actividades que favorezcan el proceso explicativo y que estén acordes a la forma de aprender de los estudiantes.

Ante esto, teniendo en cuenta las investigaciones de Morales et al. (2018), se puede resaltar que las TIC facilitan la comprensión del contenido por parte de los estudiantes. Los docentes manifiestan la dificultad explicativa para entregar algunos contenidos sin la mediación de herramientas tecnológicas (p. 554). Es decir, la explicación en clase se beneficia a través de herramientas y multimedios que diversifican la información; esto permite que el estudiante pueda codificar y entender el tema según sus diferentes formas de aprender. Lo anterior, es ratificado por los escolares al indicar que "se entiende más lo explicado" (Estudiante 13); y también, por los docentes, al confirmar que el uso de TIC "tiene una influencia positiva en la explicación del contenido" (Docente 5); aspecto de vital importancia en la educación.

En pocas palabras, la importancia que ofrece la mediación de las TIC en el mejoramiento de la explicación radica en la diversidad de ángulos y perspectivas que ofrece al estudiante. Se debe tener en cuenta que la variedad de estrategias con las que se ofrece el contenido facilitará la comprensión de este. Es por ello por lo que, en definitiva, la mediación de las TIC favorece significativamente el proceso explicativo al diversificar la entrega de contenido. Su mediación multiplica la posibilidad de convertir un aprendizaje en uno significativo.

\section{Transversalidad}

La transversalidad en las diferentes áreas de conocimiento es un aspecto para resaltar en la enseñanza mediada por TIC. Respecto a esto, los docentes manifiestan que "a través de las herramientas tecnológicas podemos trabajar, en varias áreas, la misma actividad" (Docente 4). También, con su ayuda se puede "dar cualquier tipo de contenido" (Docente 5). En breve, las TIC se convierten en un apoyo para los docentes, gracias a que permiten compartir y modificar fácilmente actividades, contenidos y estrategias sin importar el área.

Sin embargo, es necesario aclarar que lograr este proceso requiere de modificaciones estructurales en la forma de impartir el conocimiento. Pero, basados en Tixi Cujilema (2016), se podría indicar que la implementación de las TIC en la educación se convierte en un actor fundamental en dicho cambio. Esto se debe a que las TIC son herramientas que facilitan la 
construcción de nuevos conocimientos mediante experiencias virtuales que pueden ser inalcanzables físicamente (p. 3). Es decir, con la mediación de las TIC se pueden modificar algunas metodologías tradicionalistas que dificultan el acto de enseñanza, incluyendo las limitaciones de transversalidad; en tanto, con las TIC, las áreas de conocimiento no tienen un contenido específico de saberes. Es más, una de sus ventajas más notorias es la capacidad de compartir actividades, contenidos y estrategias de una forma más fácil.

Es evidente que la educación actual requiere de estrategias que permitan entrelazar los contenidos desde diversas áreas; esto con el fin de fortalecer los temas desde múltiples disciplinas, no necesariamente desde un área específica. Adicional, los estudiantes manifiestan que es de su agrado "cuando los profes dan varias actividades por Internet de diferentes materias" (Estudiante 10). Aspecto importante a la hora de entregar contenidos, pues son ellos quienes adquieren los saberes y determinan, directamente, la forma de trabajo.

\section{Flexibilización en la enseñanza}

Otra ventaja de la enseñanza mediada por TIC es la flexibilización. Según los docentes, las TIC permiten "entregar las actividades por diferentes medios" (Docente 4), y "ver los contenidos en diferentes horarios y desde diferentes lugares" (Docente 1). Partiendo de la necesidad de adaptar la educación a los diversos ritmos de aprendizaje de los estudiantes, la flexibilización por la mediación de las TIC es una de las mejores ventajas que inciden en la enseñanza.

Los docentes, basados en la investigación de Lindberg et al. (2017), consideran a las TIC como herramientas que permiten ofrecer acceso continuo del contenido al estudiante, lo cual se facilita debido a su flexibilización espacio-temporal. Por otra parte, esta flexibilidad en los contenidos ofrece una "gran posibilidad" al romper límites en la cantidad de recursos que puede utilizar el estudiantado para profundizar en un tema (pp. 126-130). En cierto sentido, no solo se benefician los estudiantes, para los cuales se desarrolla el contenido virtual; también, futuros académicos podrán observar, comparar e interpretar esta información en beneficio de sus nuevas actividades; algo que no puede realizarse mediante una metodología magistral.

De igual modo, es importante tener en cuenta que la educación no solo es un beneficio que tienen los estudiantes; es un derecho constitucional. Por ello, es importante garantizar su 
flexibilización para optimizar el acceso a ella. Algo que, con ayuda de las TIC, puede lograrse con mayor facilidad.

Así mismo, las TIC flexibilizan recursos físicos y posibilitan la enseñanza en diferentes espacios y tiempos. Su multifuncionalidad permite, desde casa, visualizar distintos espacios: museos, pirámides, zoológicos, anatomía humana en 3D, entre muchos otros. Aspectos sumamente complicados de enseñar con cualquier otro tipo de metodología. Este tipo de ventajas favorece a los estudiantes con escasos recursos; pues, como lo indican ellos mismos, "veo las actividades cuando llega mi mamá del trabajo" (Estudiante 9), debido a que muchos hogares solo cuentan con uno de estos dispositivos. El presentar actividades que se puedan ver en diferentes momentos flexibiliza el acto de enseñanza a favor del estudiantado; motivo por el cual, uno de los retos fundamentales para el docente es flexibilizar sus clases, romper la cotidianidad y fronteras espaciotemporales, con ayuda de las TIC. Las clases pueden ser diferentes, pero esta ventaja requiere su implementación.

\section{Contribuciones de las TIC como mediación pedagógica en el aprendizaje}

En esta tercera categoría se pretende detallar cómo las TIC, con su mediación pedagógica, contribuyen en la adquisición de aprendizajes en los estudiantes. Para ello, se parte de cinco categorías emergentes que se presentan a continuación:

\section{Favorecimiento del aprendizaje significativo}

La primera contribución de las TIC en el proceso de aprendizaje es su favorecimiento al aprendizaje significativo en los estudiantes. Para la definición de aprendizaje significativo se retoma la enunciación planteada por Ausubel (1983), donde manifiesta que "un aprendizaje es significativo cuando los contenidos: Son relacionados de modo no arbitrario y sustancial (...) con lo que el alumno ya sabe" (p. 2). De esta manera, se entiende "por relación sustancial y no arbitraria a las ideas que se relacionan con algún aspecto existente específicamente relevante de la estructura cognoscitiva del alumno" (Ausubel, 1983, p. 2). Es decir, se da cuando las experiencias de 
aprendizaje posibilitan a los educandos relacionar los nuevos conceptos con aquellos que ya conocen de forma previa.

Por medio de las TIC, según los docentes de la IE, "el aprendizaje se hace significativo" (Docente 2), y favorece la "adquisición de aprendizajes" (Docente 4). Esto se puede interpretar desde el uso del Internet, la variedad de recursos interactivos que ofrece y el uso de herramientas tecnológicas, como el computador y el celular. Ellas permiten acceder a contenidos e información diversa que enriquece sus saberes previos. En consecuencia, facilitan conectar y nutrir todos aquellos conceptos que traen en su estructura cognoscitiva con los nuevos aprendizajes, lo cual favorece que estos sean significativos y perdurables.

Por su parte, Hernández Requena (2008) postula que "los estudiantes tienen la oportunidad de ampliar su experiencia de aprendizaje al utilizar las nuevas tecnologías como herramientas para el aprendizaje" (p. 3). Algo también manifestado por los estudiantes, cuando indican que "las TIC ayudan en nuestro proceso de aprendizaje" (Estudiante 11). En síntesis, partiendo de las observaciones, históricos y experiencias de docentes y estudiantes, se podría inferir que estas herramientas fortalecen la construcción de aprendizajes significativos, por medio de su diversidad pedagógica e impacto generado en los estudiantes. Así pues, estos recursos fomentan experiencias que son inalcanzables en otras metodologías; experiencias novedosas, diferentes, impactantes y, por ende, ricas en nuevos conocimientos.

\section{Autonomía investigativa}

La autonomía investigativa es otra contribución de la mediación de las TIC en el aprendizaje. Aunque hay diferentes concepciones sobre autonomía, es favorable tener en cuenta la percepción de Coll et al. (2007, como se citó en Martínez-Torres y Ojeda-Gutierrez, 2016), quienes postulan que la autonomía en educación hace referencia a la capacidad del estudiante de independizarse del profesor. También, es pertinente resaltar, según la concepción de MartínezTorres y Ojeda-Gutierrez (2016), que la "autonomía es la condición del individuo para dotarse de reglas y normas de aprendizaje, en función de sus diversos niveles de exigencia, sin por ello eludir la responsabilidad de dar cuenta de sus procesos y de sus resultados" (p. 5). Dicho de otra forma, la autonomía no hace referencia a la libertad de búsqueda y pérdida de reglas en el proceso. La 
autonomía ofrece cierta independencia, respecto al acompañamiento; pero sigue siendo necesaria la contribución normativa por parte del estudiante para el cumplimiento de las actividades.

Por otra parte, y respecto a la anterior definición, mediante las actividades e instrumentos aplicados en la muestra poblacional, se logra observar el favoritismo de las TIC ante otras herramientas investigativas. Las enciclopedias, bibliotecas o recursos humanos (expertos en el tema, docentes, padres de familia), pasan a un segundo plano cuando la investigación puede ser realizada por medio de instrumentos tecnológicos.

Lo anterior puede ser explicado debido al favorecimiento de la autonomía investigativa y disponibilidad que tienen estas herramientas para los estudiantes, ofreciendo cierta independencia al estudiante y rompiendo la necesidad de acompañamiento o supervisión en el acto investigativo. Su fácil uso, diversificación de equipos y contenido ilimitado, inciden en la preferencia de este tipo de herramientas de búsqueda por parte de los escolares. Aspecto resaltado por el docente 4, cuando indica que las TIC "desarrollan el espíritu investigativo" de los estudiantes; y también por los mismos estudiantes cuando revelan que estos recursos "nos ayudan a investigar mejor" y "por mí cuenta" (Estudiante 10).

Por otra parte, en medio de las observaciones se logró evidenciar que los estudiantes amplían su experiencia educativa; por medio de las TIC ellos navegan, investigan, hacen consultas, y acceden a fuentes de información de forma autónoma. Respecto a esto, como lo afirma Hernández Requena (2008), "los alumnos no sólo obtienen información, sino que ellos mismos pueden crearla. Los estudiantes pasan de ser simples observadores (...) a estar involucrados activamente en la construcción de su conocimiento" (p. 23). Lo anterior, no solo se debe a que las diferentes herramientas que ofrece la web permiten publicar y compartir sus ideas, pensamientos y elaboraciones propias, desde lo consultado; también, al ser herramientas propias de su entorno, les permite investigar, profundizar temas, y resolver inquietudes en el preciso momento que surgen; aspecto que tiene cierto tiempo de espera en otras condiciones y, generalmente, propicia al olvido de su inquietud. 


\section{Promueve la creatividad}

La tercera contribución, la creatividad, surge del testimonio ofrecido por los docentes. Ellos indican que los trabajos mediados con estas herramientas "son entregados con mayor creatividad" (docente 3). Este tipo de testimonios permite resaltar cómo las TIC desarrollan el imaginario y la capacidad de creación de los estudiantes.

Respecto a lo anterior, es necesario recordar que las TIC permiten la interacción de los educandos con diferentes tipos de herramientas llevadas a clase (gráficos, imágenes, audios y demás). Aspecto que propicia la visualización de la diversidad de colores, formas y diseños. En pocas palabras, cuando el estudiante aprende los contenidos con diferentes estrategias, indirectamente aprenden diferentes alternativas para la elaboración de actividades académicas.

También, como lo indica Hernández Requena (2008) "los sonidos y las imágenes son herramientas que fomentan la creatividad de los estudiantes, estimulando su aprendizaje al crear riqueza en el contexto impartido" (p. 5); aspecto que se ve complementado por los escolares al indicar que "pueden ver diferentes cosas para hacer" (Estudiante 13), y que esto les permite "tener mucha imaginación" (Estudiante 14), entre otras cosas. La calidad del sonido, las imágenes y los demás recursos los motivan en su proceso creativo durante el desarrollo de las actividades académicas; esto hace que el ambiente escolar sea mucho más rico y variado, favoreciendo así el proceso de aprendizaje.

\section{Actividades escolares}

Partiendo de las respuestas obtenidas en los grupos focales, se encontró que las TIC contribuyen en el desarrollo de múltiples actividades escolares, como tareas, investigaciones, ejercicios de clase, entre otras. Algunos estudiantes resaltan que "la tecnología (...) sirve para muchas cosas, ejemplo (...) ayuda hacer las tareas bien" (Estudiante 24). Otros estudiantes manifiestan que "ayuda en las actividades del colegio" (estudiante 14), y "a encontrar mi tarea con más facilidad" (estudiante 8). Aspecto que es importante destacar, debido a la necesidad de investigar y acudir a información diferente a la suministrada en las IE. 
La realización de actividades en las que se vinculan las TIC ofrece mayor facilidad al estudiante para el desarrollo de sus compromisos escolares. Lo anterior, puesto que, según lo expresado por los educandos, les facilita la realización de tareas, consultas y demás ejercicios al encontrar diferentes contenidos y medios para la comprensión de los temas.

Finalmente, Hernández Requena (2008) manifiesta que la conexión que existe entre la tecnología y el aprendizaje se debe a que "las nuevas tecnologías, si son utilizadas de manera efectiva (...) coinciden mucho más con la manera como las personas aprenden" (p. 7). Desde este punto de vista, las TIC favorecen la comprensión de los contenidos abordados; es decir, si un estudiante no entiende un tema, los recursos tecnológicos ayudan a su asimilación, lo que posibilita el desarrollo de sus compromisos escolares.

\section{Comunicación}

Aunque las TIC son herramientas altamente conocidas por los estudiantes, desde su perspectiva, la tecnología es muy importante porque permite la comunicación con familiares y amigos. El estudiantado manifiesta su importancia con base en la facilidad de la comunicación entre ellos y profesores; tanto así que suelen indicar que estos recursos se han vuelto algo necesario en sus vidas, con frases como: "considero la tecnología algo muy importante en nuestra vida cotidiana" (estudiante 8).

Sin embargo, teniendo en cuenta la infinidad de herramientas de comunicación que conocen los estudiantes y que permiten interactuar con otras personas de forma virtual (chats, redes sociales, correos, juegos online, foros, páginas web y demás), es adecuado mencionar que la presente investigación no solo pretende destacar el valor que pueden ejercer las TIC en el acto comunicativo.

Según Morze et al. (2016), basados en la información ofrecida por diferentes autores (OED, 2015; WTID, 1993; Boston KM, 2014; Martínez-Moyano, 2006), la comunicación es definida normalmente como un proceso de transferencia de información entre dos o más seres. También, sirve como medio para conectar personas y lugares (p. 352). Sin embargo, el eje en esta investigación se orienta en cómo la mediación de las TIC favorece la comunicación de los estudiantes, y por ende su aprendizaje. 
Al respecto, Siemens (2004/2007) expresa que "el aprendizaje (...) puede residir fuera de nosotros (...) está enfocado en conectar conjuntos de información especializada, y las conexiones que nos permiten aprender más tienen mayor importancia que nuestro estado actual de conocimiento" (p. 6). Sin embargo, esta información especializada no solo hace referencia al contenido; el aprendizaje, y su connotación, surgen de la forma como se obtenga esta información. Por tanto, el medio de comunicación y la forma en que se comunique puede variar altamente lo adquirido por el estudiante.

Por otra parte, algo importante a destacar en la mediación pedagógica de las TIC es la forma de expresión con la que se imparte la información; es decir, una contribución adicional de estas herramientas es su pertinencia comunicativa. Esto se debe al impacto y a la trascendencia que genera el contenido cuando es mediado por herramientas tecnológicas. Para este caso, la estética, los colores, la forma, el brillo, el sonido, la imagen, el movimiento, entre otros aspectos, sí importan. En efecto, teniendo en cuenta que la comunicación por medio de este tipo de recursos favorece la expresividad, visualización, el tratamiento de formas y contenidos, la comunicación mediada por las TIC favorece el aprendizaje en los estudiantes.

En síntesis, estas herramientas contribuyen al proceso comunicativo especializado. $\mathrm{Su}$ estética, sus colores, su diseño innovador y su pertinencia contribuyen al aprendizaje mediante el impacto a los estímulos (intereses, expectativas, experiencias, necesidades) de los estudiantes (Ortiz Ocaña, 2015, pp. 77-78). La mediación de las TIC permite una apropiación, a través de su estética y dinamismo, de contenidos fuera del rubro explicativo. A parte de suministrar información y mediar en su entendimiento, su contribución fomenta la adquisición y el dominio de nuevas ideas. En otras palabras, la facilidad y diversidad comunicativa de estos recursos tecnológicos fomentan muchos más aspectos que el mero acto comunicativo.

\section{Discusión}

El propósito de la investigación fue analizar la incidencia que tiene la aplicación de las tecnologías de la información y la comunicación, como mediación pedagógica, en los procesos de enseñanza y aprendizaje de los grados quinto, de la IE Barrio París del municipio de Bello. Encontrándose que inciden en la forma de llevar los contenidos a los estudiantes, para que sean 
mucho más atractivos y cautivadores de su atención e interés. Este tipo de herramientas aportan elementos didácticos y mediadores en las aulas de clase, buscando que estas sean más atractivas. $\mathrm{Al}$ ofrecer elementos dinamizadores desde los recursos de la web, se incide en los procesos de enseñanza de los docentes y de aprendizaje de los educandos, haciendo estos procesos más significativos. Por ende, se favorece la motivación, participación, comunicación, creatividad, investigación, trabajo en equipo y concentración de la atención.

Los resultados evidencian algunas relaciones, entre la actual investigación y el mismo objeto de estudio, por parte de diferentes investigadores. Según Lanuza Gámez et al. (2018, pp. 27-29), las TIC permiten dinamizar los procesos de enseñanza y aprendizaje, haciendo que estos procesos sean significativos y dinámicos; además, amplían las oportunidades de acceso a la información y el análisis de esta, debido a las simulaciones que proporciona. Lo anterior, apoya, ciertamente, el presente estudio, debido a que se encontró cómo la mediación de estas tecnologías propicia el conocimiento de los educandos, logrando, de esta manera, que sean significativos, perdurables y relacionales. Es decir, que el estudiante conecte sus saberes previos con lo nuevo por aprender y, además, favorecer su creatividad, comunicación, investigación y desempeño en el desarrollo de actividades escolares; puesto que, al contar con el disfrute de una mediación atractiva, se concentran mucho más en los contenidos, y se promueve la capacidad de profundización.

Desde la investigación de Lanuza Gámez et al. (2018, p. 27), uno de los aspectos negativos de las TIC es la distracción que genera en los estudiantes, quienes alejan su atención de la temática de las clases por otro tipo de información. Esto se puede contrastar con los hallazgos del actual estudio, donde se evidenció cómo las TIC, en lugar de dispersarlos, logra favorecer la concentración de la atención de los estudiantes; permitiendo, de esta manera, que puedan focalizar su pensamiento y estructura cognitiva por mayor tiempo en una tarea determinada, debido a la motivación y atracción que le generan este tipo de herramientas. Este es uno de los hallazgos que diferencian la actual investigación de los estudios de Lanuza Gámez et al. (2018), y aportan un valor agregado a la comunidad científica.

Como lo sugieren los hallazgos, las TIC favorecen el aprendizaje significativo, permitiendo que los estudiantes establezcan procesos de conexión con sus saberes previos. Además, en la medida que investigan de forma autónoma, logran reconstruir significados y ven favorecida su creatividad. Esto se debe al uso de herramientas que permiten crear contenidos, producir textos, 
imágenes y diferentes recursos en la web, de forma variada. Lo anterior, resulta intrigante al compararse con los estudios realizados por Gómez y Álvarez (2020), quienes encuentran que en diferentes escuelas "las salas no están ocupadas con las computadoras necesarias y que en ocasiones no se pueden utilizar algunas por desperfectos técnicos" (p. 18). Por ello, cabe preguntarse, para futuras investigaciones, por la falta de adecuación de recursos tecnológicos en las escuelas, especialmente las computadoras, en relación con la multiplicidad de ventajas que se evidenciaron en la actual investigación, para los procesos de enseñanza y aprendizaje.

Complementando lo anterior, se encuentra en las investigaciones de Onyema et al. (2020, p. 111) que, por producto de la pandemia del COVID-19, las escuelas en cientos de países asumieron una educación a distancia, aprovechando las posibilidades que ofrecen las TIC. Sin embargo, no solamente se encontró el poco acceso de muchos estudiantes que carecían de recursos tecnológicos; también, se evidenció docentes poco familiarizados con este tipo de herramientas, lo cual permite reflexionar, desde la actual investigación, en el reto que tienen los docentes, el sector educativo y el Gobierno en general, para actualizar los métodos de enseñanza, teniendo las TIC como mediación pedagógica, puesto que no había preparación para el uso de este tipo de herramientas, aun siendo la respuesta a una educación innovadora que propende por el avance de la sociedad y procesos de aprendizaje significativo, tanto a distancia como al interior de aulas de clase presenciales.

Otro punto para discutir en la investigación son las ventajas del proceso de enseñanza mediado por las TIC, en tanto se evidenció su favorecimiento en la variedad de estrategias pedagógicas que aporta a los docentes como utilidad práctica para cualificar su labor. Logrando con ello transversalizar y flexibilizar las temáticas, al ritmo, tiempo y modo en la que los estudiantes aprenden. De esta manera, mejoran la explicación, para que estos procesos puedan darse desde la distancia y adaptarse a las particularidades de ellos. De igual modo, ofrecen recursos interactivos que hacen posible el trabajo en equipo, por medio de la comunicación a distancia, con el uso de plataformas y chats.

Todo esto, conlleva a repensar los modelos de enseñanza utilizados en la escuela, los cuales requieren actualizarse para dar respuesta a una nueva generación permeada por las TIC. Según lo hallado en esta investigación, la Internet es uno de los principales recursos en la elaboración de sus actividades académicas, lo que contribuye en su aprendizaje. Es por esto por lo que, como 
implicación práctica de este estudio, se reta a los docentes no solamente a utilizar las nuevas tecnologías de forma esporádica, sino, también, a replantear los métodos de enseñanza por aquellos que sean menos tradicionales, más participativos y con mayor construcción del conocimiento autónomo. Esto puede favorecerse a través de la mediación y multiplicidad de ventajas mencionadas en la actual investigación, teniendo en cuenta que las TIC son útiles a los docentes como mediación pedagógica, y aportan formas atractivas y variadas de enseñar; además, enriquecen el acto educativo y lo hacen significativo para el estudiante, el cual, a su vez, encuentra en ellas elementos motivacionales y diversos para construir conocimientos.

Por otra parte, algunos puntos fuertes a resaltar del estudio son el análisis de las evidencias, según tres categorías, que surgieron de la pregunta de investigación y el objetivo general; estas son: incidencia de las TIC como mediación pedagógica, ventajas de los procesos de enseñanza y las contribuciones en los procesos de aprendizaje. Hacer el análisis de esta forma posibilitó particularizar cada uno de los aspectos que era necesario investigar y ver de forma más detallada. Lo anterior, no solo desde el punto de vista de docentes y estudiantes, sino también de los investigadores y fuentes secundarias, como expertos teóricos consultados.

Otra ventaja de la investigación fue el uso de un enfoque cualitativo que posibilitó una recolección de la información de forma flexible, permitiendo realizar nuevas preguntas en el camino e ir resolviéndolas o devolverse de ser necesario. Así mismo, el eje principal fueron los hechos, y según estos se indagó lo dicho por teóricos expertos que pudieran aportar al respecto.

La aplicación de las técnicas e instrumentos que hicieron parte del trabajo de campo estuvieron programadas de forma presencial; sin embargo, por motivo de la pandemia del COVID19, que arribó en el país y provocó el aislamiento social establecido en el Decreto 457 de 2020, y con ello el cierre de las escuelas, hubo que reinventarse y culminar la aplicación de estas por medios virtuales. Aunque esto se consideró un limitante en algún momento de la investigación, posteriormente fue un punto a favor de esta, ya que permitió visualizar el uso y acercamiento de los estudiantes con las TIC, convirtiéndose en un punto focal para la recolección de la información.

Otra de las limitaciones encontradas durante la investigación fue el paso de la población de un grado a otro, lo cual modificó la muestra. Esto conllevó a repetir los instrumentos aplicados y modificó los resultados encontrados. Entendiéndose que los grupos son diversos y así mismo sus particularidades. 


\section{Conclusiones}

La investigación logró analizar la incidencia de las TIC como mediación pedagógica en los procesos de enseñanza y aprendizaje de los grados quinto de primaria de la IE Barrio París, dando cumplimiento a los objetivos de estudio que dieron luz a las categorías: incidencia de las TIC como mediación pedagógica, sus ventajas en el proceso de enseñanza y sus contribuciones en el aprendizaje. Así las cosas, es posible indicar que su inclusión en los aspectos pedagógicos fortalece los diferentes procesos educativos, haciéndolos más significativos y constructivistas.

Desde el problema planteado: ¿Cómo inciden las TIC como mediación pedagógica en los procesos de enseñanza y aprendizaje?, se permitió encontrar que los avances tecnológicos que movilizan a las nuevas generaciones y tocan el sistema educativo tienen una incidencia importante en los aspectos pedagógicos. Estos posibilitan nuevas formas de tratar los contenidos en las aulas de clase, haciendo que estas cuenten con recursos útiles para el uso de mediaciones educativas en los procesos de enseñanza y aprendizaje. Es por ello por lo que las TIC no sólo ofrecen utilidad social o de comunicación, también son aplicadas como mediación pedagógica en la escuela, favoreciendo el tratamiento de contenidos, con ventajas para los docentes y contribuciones en los estudiantes.

En el proceso de enseñanza, su incidencia se concretiza en la variedad de herramientas tecnológicas; estas posibilitan al docente diferentes formas de llevar su acto educativo a los estudiantes, mejorando así la explicación. Además, ofrecen flexibilidad de tiempo, espacio, trabajo en equipo y la posibilidad de transversalizar todas las áreas.

En el proceso de aprendizaje se evidenciaron incidencias que contribuyen a que su adquisición sea significativa en los estudiantes. Las diferentes formas que ofrece la mediación de las TIC permiten conectar sus saberes previos con los nuevos. Lo anterior promueve la creatividad, la autonomía investigativa y la comunicación en el desarrollo de actividades escolares, al mismo tiempo que detonan su motivación. Lo anterior, conlleva a activar su participación y mejorar la concentración de atención por parte del estudiante.

Desde lo evidenciado en esta investigación, fue posible comparar y relacionar los hallazgos con diferentes estudios, los cuales tenían como objeto el uso de las TIC en entornos escolares. Se 
encontraron puntos de relación que permitieron resaltar el favorecimiento del uso de las herramientas tecnológicas, como mediación pedagógica, en los procesos de enseñanza y aprendizaje. Uno de ellos refiere al aprendizaje significativo, debido a la concentración con la que los estudiantes participan; aspecto altamente superior, en comparación con otras clases en las que no se utilizan este tipo de recursos.

Una de las implicaciones en el proceso de aprendizaje de los estudiantes fue la motivación; aspecto que demostró su carácter fundamental en la elaboración de las actividades escolares. Por lo que, sin importar si un padre o madre de familia está pendiente del horario, actividades, trabajos, talleres, evaluaciones y demás procesos educativos, permite que los educandos cumplan con todos sus requerimientos sin tener un "guardia" controlando lo que hace. Pero, sin motivación, aunque esta persona esté siempre al lado del escolar, ¿se podría garantizar que cumpla con sus actividades y, en medio del proceso, comprenda la información que se le ofrece?

La actual investigación ofrece a la comunidad educativa y científica un aspecto diferenciador con otras investigaciones. En esta se encontró que las TIC, como mediación pedagógica, inciden en la forma de tratar los contenidos para hacer posible el acto de enseñanza de forma atractiva, expresiva, original y acorde con la forma en la que aprenden los estudiantes; lo cual, mediante las observaciones detalladas, propicia el aprendizaje significativo.

Así mismo, otra de las incidencias de la investigación, desde la interpretación de los datos, fue el aporte de las TIC en lo pedagógico; puesto que reta e invita al profesor a innovar en su práctica y rol de enseñar. Esto debido a la variedad de recursos que son necesarios explorar, aplicar y usar en las clases de manera adecuada, con intención y sentido educativo; de tal forma que los estudiantes se apropien, interactúen y aprendan con ellas.

Es de resaltar que no se esperaba, durante la investigación, la participación de los más tímidos, lo cual pudo darse gracias a las mediaciones tecnológicas, donde encontraron la forma de aportar sin necesidad de estar frente a un público de forma presencial. Es pertinente mencionar la riqueza en estrategias que se pueden observar en las clases mediadas por TIC, en comparación con otras clases sin estos instrumentos, lo que convierte a la educación en un proceso divertido y fuera de la rutina. Por esto, se considera un elemento innovador que enriquece las aulas con múltiples estrategias para fortalecer los lazos educacionales con sus estudiantes. 
Este proyecto muestra la importancia de factores que, en ocasiones, pasan desapercibidos en el proceso de enseñanza y aprendizaje. Es fundamental que, en el proceso de educación, los docentes innoven en sus metodologías didácticas por medio del uso de herramientas tecnológicas. Lo anterior, con el fin de convertir los conocimientos más significativos, motivadores y autónomos. Es así por lo que la enseñanza se da de una manera más didáctica y, por ende, permite que los estudiantes comprendan su entorno, la información que se les ofrece, y sepan buscar y utilizar esta información por medio de las TIC.

En el marco de los resultados obtenidos se sugiere, para futuras líneas de investigación, poder realizar un análisis de diferentes grupos por varios años, lo cual permita determinar cuáles hallazgos logran permanecer a través del tiempo, como una constante general, y cuáles son particulares de cada grupo. Asimismo, poder hacer seguimiento al grupo investigado y analizar cómo inciden las mediaciones tecnológicas según los cambios en los ciclos de edad de los estudiantes.

Finalmente, se sugiere determinar, a fondo, cómo las TIC aportan a los diferentes modelos de enseñanza educativa utilizados por los docentes en la escuela, teniendo en cuenta que, aunque es un recurso de mediación pedagógica, muchos docentes aún se encuentran arraigados a métodos diversos, los cuales resultan muchas veces tradicionales.

\section{Referencias}

Agudelo Ceballos, E. J., y Valencia Arias, A. (2018). La gestión del conocimiento, una política organizational para la empresa de hoy. Ingeniare, 26(4), 673-684. http://dx.doi.org/10.4067/S0718-33052018000400673

Alarcón, P., López, D., y Rodríguez, M. (2015). Metodología y herramienta TIC de apoyo a la acción tutorial en el marco del EES. En M. Mut Camacho (Coord.), Procesos de Aprendizaje de vanguardia en la Enseñanza Superior (pp. 67-87). ACCI. https://bit.ly/30qNzXp

Albrecht, J. R., \& Karabenick, S. A. (2018). Relevance of learning and motivation in education [Relevancia del aprendizaje y la motivación en la educación]. The Journal of Experimental Education, 86(1), 1-10. https://doi.org/10.1080/00220973.2017.1380593 
Arriazu Muñoz, R. (2015). La incidencia de la brecha digital y la exclusión social tecnológica: el impacto de las competencias digitales en los colectivos vulnerables. Praxis Sociológica, (19), 225-240. https://dialnet.unirioja.es/servlet/articulo?codigo =5383986

Ausubel, D. (1983). Teoría del Aprendizaje Significativo. http://files.gersain.webnode.es/200000026-7721a781a1/Aprendizaje_significativo.pdf

Benítez Díaz, L. M., Sevillano García, M. L., \& Vázquez Cano, E. (2019). Effects on academic performance in secondary students according to the use of ICT [Efectos sobre el rendimiento académico en estudiantes de secundaria según el uso de las TIC]. International Journal of Educational Research and Innovation, (12), 90-108. https://doi.org/10.46661/ijeri.4045

Borrero-Puentes, N., \& Alcalá-Zarate, L. F. (2020). Modelo de gestión de equipos virtuales en la ejecución de proyectos académicos colaborativos. Revista CEA, 6(12), 147-166. https://doi.org/10.22430/24223182.1609\}

Carneiro R., Toscano J. C., y Díaz T. (Coords.). (2019). Los desafíos de las TIC para el cambio educativo. $\quad$ Fundación Santillana. http://190.57.147.202:90/jspui/bitstream/123456789/438/1/LOS\%20DESAFIOS\%20DE \%20LAS\%20TICS\%20PARA\%20EL\%20CAMBIO\%20EDUCATIVO.pdf

Espinel Armas, E. E. (mayo-agosto, 2020). La tecnología en el aprendizaje del estudiantado de la Facultad de Ciencias Químicas, Universidad Central del Ecuador. Revista Actualidades Investigativas en Educación, 20(2), 1-37 http://dx.doi.org/10.15517/aie.v20i2.41653

Gómez, V. L., y Álvarez, G. (2020). Tecnologías digitales en la escuela primaria: las perspectivas de los docentes sobre su inclusión y la enseñanza en las aulas. Virtual, Educación y Ciencia, 11(20), 9-26. https://dialnet.unirioja.es/servlet/articulo?codigo=7869085

Hernández Requena, S. (2008). El modelo constructivista con las nuevas tecnologías: aplicado en el proceso de aprendizaje. RUSC. Universities and Knowledge Society Journal, 5(2), 2635. https://www.redalyc.org/pdf/780/78011201008.pdf

Hernández Sampieri, R., Fernández Collado, C., y Baptista Lucio, P. (2018). Metodología de la investigación ( $6^{\mathrm{a}}$ Ed.). McGRAW-HILL. http://observatorio.epacartagena.gov.co/wpcontent/uploads/2017/08/metodologia-de-la-investigacion-sexta-edicion.compressed.pdf 
Hernández, R. M. (enero-junio, 2017). Impact of ICT on Education: Challenges and Perspectives [Impacto de las TIC en la educación: desafíos y perspectivas]. Propósitos y Representaciones, 5(1), 325-347. http://dx.doi.org/10.20511/pyr2017.v5n1.149

Lanuza Gámez, F. I., Rizo Rodríguez, M., y Saavedra Torres, L. E. (2018). Uso y aplicación de las TIC en el proceso de enseñanza-aprendizaje. Revista Científica De FAREM-Estelí,(25), 16-30. https://doi.org/10.5377/farem.v0i25.5667

Lindberg, O. J., Olofsson, A. D., \& Fransson, G. (2017). Same but different? An examination of Swedish upper secondary school teacher's and student's views and use of ICT in education [¿Lo mismo pero diferente? Un examen de las opiniones de los profesores y alumnos de la enseñanza secundaria superior sueca y del uso de las TIC en la educación. International Journal of Information and Learning Technology, 34(2).122-132. https://doi.org/10.1108/IJILT-09-2016-0043

Macià Bordalba, M. (2016). La comunicación familia-escuela: el uso de las TIC en los centros de primaria. Revista Electrónica Interuniversitaria de Formación del Profesorado, 19(1), 7383. http://dx.doi.org/10.6018/reifop.19.1.245841

Martínez-Torres, R. E., y Ojeda-Gutierrez, M. (2016). ¿Cómo medir la autonomía de estudiantes en la Educación Superior? Revista de Investigaciones Sociales, 2(3), 1-12. https://www.ecorfan.org/republicofnicaragua/researchjournal/investigacionessociales/jour nal/vol2num3/Revista_de_Investigaciones_Sociales_V2_N3_1.pdf

Morales, P., Escandell, M. O., y Castro, J. J. (2018). Formación del profesorado en TIC y su pensamiento acerca de la integración de la tecnología en la enseñanza de adultos. Profesorado. Revista de Currículum y Formación del Profesorado, 22(1), 541-560. https://doi.org/10.30827/profesorado.v22i1.9941

Morze, N., Makhachashvili, R., \& Smyrnova-Trybulska, E. (2016). Communication in education: ICT tools assessment [Comunicación en educación: evaluación de herramientas TIC]. En M. Turčáni, Z. Balogh, M. Munk, \& L., Benko (Eds.), 11th International Scientific Conference on Distance Learning in Applied Informatics (pp. 351-364). Wolters Kluwer.

Mosquera-González, D., Valencia-Arias, A., Benjumea-Arias, M., y Palacios-Moya, L. (2021). Factores asociados al uso de tecnologías de la información y la comunicación (TIC) en los 
procesos de aprendizaje de estudiantes de ingeniería. Formación Universitaria, 14(2), 121132. http://dx.doi.org/10.4067/S0718-50062020000500077

Onyema, E. M., Eucheria, N. C., Obafemi, F. A., Sen, S., Atonye, F. G., Sharma, A., \& Alsayed, A. O. (2020). Impact of Coronavirus pandemic on education [Impacto de la pandemia del coronavirus en la educación]. Journal of Education and Practice, 11(13), 108-121. https://genbase.iiep.unesco.org/workspace/applis/epidoc/fichiers/EPIDOC/38698_52821_ 56584_1_PB.pdf

Ortiz Ocaña, A. (2015). Neuroeducación. ¿Cómo aprende el cerebro humano y cómo deberían enseñar los docentes? Ediciones de la U. https://bit.ly/3pZxaBZ

Patiño-Toro, O. N., Bermeo-Giraldo, C., Valencia-Arias, A., y Garcés-Giraldo, L. F. (2020). Factores que inciden en el aprendizaje en gestión tecnológica e innovación en estudiantes de administración mediante el modelo de aceptación tecnológica. Formación Universitaria, 13(5), 77-86. http://dx.doi.org/10.4067/S0718-50062020000500077

Pérez-Ortega, I. (2017). Creación de Recursos Educativos Digitales: Reflexiones sobre Innovación Educativa con TIC. International Journal of Sociology of Education, 6(2), 244-268. https://doi.org/10.17583/rise.2017.2544

Porcar Marín, Ó. (2018). La Gamificación, una solución para la falta de motivación y escasez de participación en clase [Trabajo de grado de maestría]. Universitat Jaume I. http://hdl.handle.net/10234/180113

Presidencia de la República de Colombia. (22 de marzo de 2020). Decreto Número 457, por el cual se imparten instrucciones en virtud de la emergencia sanitaria generada por la pandemia del Coronavirus COVID-19 y el mantenimiento del orden público. https://dapre.presidencia.gov.co/normativa/normativa/DECRETO\%20457\%20DEL\%202 2\%20DE\%20MARZO\%20DE\%202020.pdf

Puerta Gil, C. A. (2016). El acompañamiento educativo como estrategia de cercanía impulsadora del aprendizaje del estudiante. Revista Virtual Universidad Católica del Norte, (49), 1-6. https://revistavirtual.ucn.edu.co/index.php/RevistaUCN/article/view/794/1314

Siemens, G. (2007). Conectivismo: Una teoría de aprendizaje para la era digital (D. E. Leal, Trads.) [Trabajo original publicado en 2004). https://skat.ihmc.us/rid=1J134XMRS- 


\section{Mediación en el}

\section{aula}

Mediación en el aula | Revista Virtual Universidad Católica del Norte, 65, 66-101

ISSN: 0124-5821 (En línea)

\section{ZNMYT4-13CN/George\%20Siemens\%20-\%20Conectivismo-}

una\%20teor\%C3\%ADa\%20de\%20aprendizaje\%20para\%20la\%20era\%20digital.pdf

Tixi Cujilema, N. D. R. (2016). Proyecto TICs y educación en estudios sociales [Tesis de grado de Licenciatura). Universidad Técnica de Cotopaxi. http://repositorio.utc.edu.ec/handle/27000/4153

Wang, L., \& Xiong, C. (2019). A novel methodology of sequential optimization and nonprobabilistic time-dependent reliability analysis for multidisciplinary systems. https://doi.org/10.1016/j.cma.2017.08.023

Yong Castillo, E., Nagles García, N., Mejía Corredor, C. y Chaparro Malaver, C. E. (febrero-mayo, 2017). Evolución de la educación superior a distancia: desafíos y oportunidades para su mejora. Revista Virtual Universidad Católica del Norte, (50), 80-105. https://revistavirtual.ucn.edu.co/index.php/RevistaUCN/article/view/814/1332 